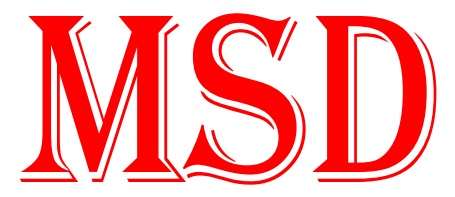

Medical Science and Discovery ISSN: 2148-6832

\section{Improving baseline serological investigations for dental workers at specialized dental center}

\author{
Ahmad Alzahrani ${ }^{1}$, Hanady Idreis $^{2}$, Haifa Abdulghaffar ${ }^{3}$, Layali Alakkad ${ }^{4}$ \\ 1 Saudi Board of Preventive Medicine, Public Health Department, Jeddah, Saudi Arabia. \\ 2 Occupational health clinic, King Fahad Hospital, Jeddah, Saudi Arabia. \\ 3 Dental specialty center, King Fahd Hospital, Jeddah, Saudi Arabia. \\ 4 Infection control, dental specialty center, King Fahad Hospital, Jeddah, Saudi Arabia. \\ * Corresponding Author: Ahmad Alzahrani E-mail: ahmad96@hotmail.com
}

\section{ABSTRACT}

Objective: Serological tests for dental workers have been suggested by different international agencies to ensure the safety of dental practitioners and, subsequently, their patients. In our organization, the percentage of dental workers who underwent serological tests was low (26\%).

Material and Methods: An intervention was designed using three sequential PDSA cycles to test changes proposed by team members. The percentage of dental workers who underwent these tests was used as the measure.

Results: During the project period, the percentage of dental workers who underwent serological tests within nine months increased from $24 \%$ to $87 \%$. Amongst the three interventions, the final one exhibited the most prominent change leading to major improvement.

Conclusion: Serological tests are essential investigational data used to ensure the safety of dental workers, which subsequently also enhances patient safety. Further interventions are highly recommended to maximize the number of dental workers who undergo serological investigation.

Keywords: Dental health services, occupational health, and quality improvement.

\section{INTRODUCTION}

Few dental workers in our center underwent baseline serological tests for main bloodborne viruses (BBV), ranging from 24\% to 26\% (Figure 1).

A brainstorming meeting with team members was held in our facility to determine the possible causes of this low percentage, wherein a whiteboard was used to organize the causes into four categories (Figure 2). This project aimed to increase the percentage of dental workers undergoing baseline serologic tests to $80 \%$ in our dental center during the period from October 2020 to June 2021.

\section{Research Article}

Received 21-12-2021

Accepted 04-01-2022

Available Online: 07-01-2022

Published 30-01-2022

Distributed under

Creative Commons CC-BY-NC 4.0

\section{OPEN ACCESS}

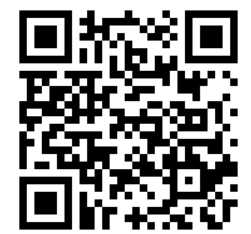

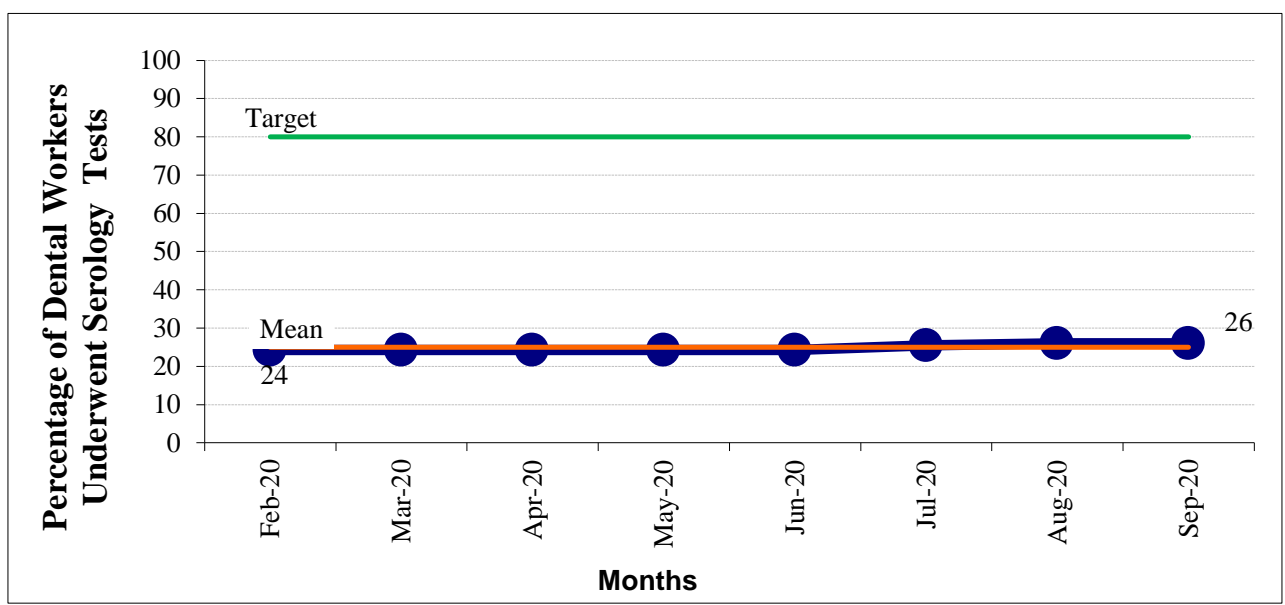

Figure 1: Shows the percentage of dental workers who underwent baseline serological tests from February 2020 to September 2020. 


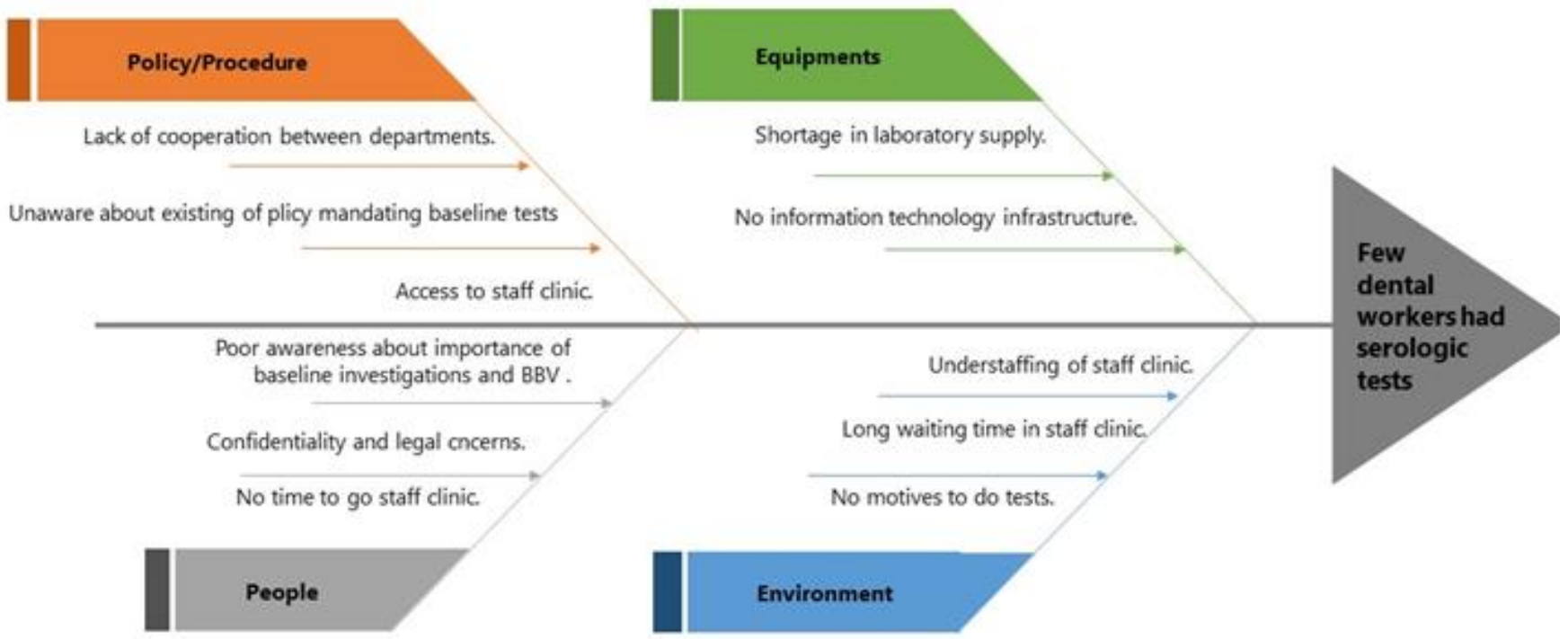

Figure 2: Fishbone diagram shows the root cause analysis of the problem.

Healthcare workers are prone to healthcare-associated infections. Common infections are those caused by bloodborne viruses (BBV), namely human immunodeficiency virus (HIV), hepatitis virus (HBV), and hepatitis C virus (HCV) (1).

Dental workers are exposed directly to microorganisms and this exposure contributes to increased infections with hepatitis $\mathrm{B}$, hepatitis $\mathrm{C}$, tuberculosis, and the human immunodeficiency virus (HIV)(2). Some studies reported that $78.3 \%$ of dental workers had attended patients with infectious diseases (3).

Several international agencies have suggested periodic serological testing for all healthcare workers (4). It has also been suggested that healthcare workers performing exposureprone procedures must take reasonable steps to monitor their BBV status and should be tested for BBVs at least once every three years. Some countries are encouraging healthcare workers to undergo BBP screening but does not mandate it (1). Baseline serological tests for dental workers have been recommended by Dental Infection Control Audit in Saudi Ministry of Health (5).

Since BBV can be asymptomatic for long time, or cause mild symptoms that may go unnoticed, it is possible for a healthcare worker to be unknowingly infected. This delay in diagnosis can lead to the development of complications related to the infection and increase the risk of transmitting the virus to family members, other close contacts, or even patients (4).

\section{MEASUREMENT}

The percentage of dental workers who underwent baseline serologic tests was used as a process measure to track the improvement of the planned interventions. Operationally, the numerator is the number of dental workers who underwent baseline serologic tests in our dental center, while the denominator is the total number of dental workers in the same center and period.

To calculate this measure, we retrieved data from OASIS software (platform for ordering and tracking investigations in our organization) on a monthly basis. The baseline measurements are shown in (Figure 1).

\section{DESIGN}

The team members used several quality tools to best understand and improve this opportunity. Brainstorming; cause and effect (Ishikawa) model; and nominal group technique, among others, were used by our multidisciplinary team. The proposed interventions are listed in (Table 1).

The Model for Improvement (MFI) was used to test the effect of these selected changes by conducting sequential PDSA cycles for one month for each change.

The team members include the dental center director, dental infection control supervisor, occupational health clinic doctor, and quality advisor.

Table 1: shows potential solutions (changes ideas).

\begin{tabular}{lcc} 
Chosen Change Ideas & Mechanism & Predicted Result \\
$\begin{array}{l}\text { Sending text messages to dental workers about } \\
\text { importance of baseline serologic tests. }\end{array}$ & Increasing awareness. & Mild improvement. \\
$\begin{array}{l}\text { Conducting counselling sessions to raise } \\
\text { awareness about importance of these tests on } \\
\text { individual bases. }\end{array}$ & Increasing awareness. & Good response \\
$\begin{array}{l}\text { Bundled coordination and awareness actions. } \\
\text { Providing easy referral to staff clinic. }\end{array}$ & Optimum response. \\
\hline
\end{tabular}




\section{STRATEGY}

The overall aim of our project was to follow SMART criteria to increase the percentage of dental workers undergoing baseline serologic tests in our dental center to $80 \%$ during the period from October 2020 to June 2021. To achieve this ambitious aim, we executed three sequential PDSA cycles (see Supplement 1).

PDSA cycle 1: The first intervention was to send awareness text messages about the importance of baseline serological tests, which were carried out by a dentist. This change achieved a percentage of $34 \%$ in our measure. Feedback revealed that some patients (staff) were late for their appointments and that many other dental workers (non-staff dentists) came to request the annual tests; additionally, prediction of an increase in the measure was unfortunately not sufficient.

PDSA cycle 2: To facilitate greater progress, we conducted educational sessions to raise awareness about the importance of these tests on individual bases. The result was a slight increase in measure 36 only. Feedback from the team revealed resistance from different departments (dental, staff clinic, and laboratory) as well as a problematic referral process.

PDSA cycle 3: We decided to tackle this opportunity through a multitasking approach targeting awareness and the referral process simultaneously. The bundled intervention was suggested and implemented through the delivery of capacitation courses to enhance knowledge about the importance of infection control practices as well as bloodborne pathogens and the risk of healthcare-associated infections. Furthermore, the team reengineered the referral process through collaboration with related departments (i.e., staff clinic and laboratory). The achieved percentage reflected improvement to the value of $87 \%$, which was built progressively during the four months following this cycle. Feedback demonstrated a high satisfaction rate among dental workers.

\section{RESULTS}

Our main outcome measure was the percentage of dental workers undergoing baseline serologic tests in our dental center during the period from October 2020 to June 2021. The measurement was achieved by dividing the number of staff members who underwent the tests by the total number of dental workers in the center on a monthly basis.

The baseline level was as low as $24 \%-26 \%$ during the period from February to September 2020. The first interventions were executed in October 2020, resulting in a mild improvement to $27 \%$; following the second intervention, this increased to $34 \%$.

Due to the latent effect, the team required four months of monitoring after the third intervention to observe the improvement, which reached $87 \%$ in June 2021 (see Figure3).

Since all data from the laboratory investigations were retrieved through the organization's Oasis software, to the best of our knowledge, we did not encounter the issue of missing data.

After executing the first two interventions, the team observed resistance from dental staff and related departments. Such resistance encouraged us to consider a more organized and cooperative intervention, namely the third PDSA cycle, which tackled both awareness and the referral process.

Overall, the unintended consequences throughout this journey can be summarized as follows: workload among occupational health clinic staff; shortage of some medical equipment; time wasted in additional discussion with some patients in the staff clinic; hesitancy of some staff to receive vaccination; and the necessity of further investigation. Some COVID-19 regulations, such as limitations on attendance at any gathering, inversely affected the progress of the project.
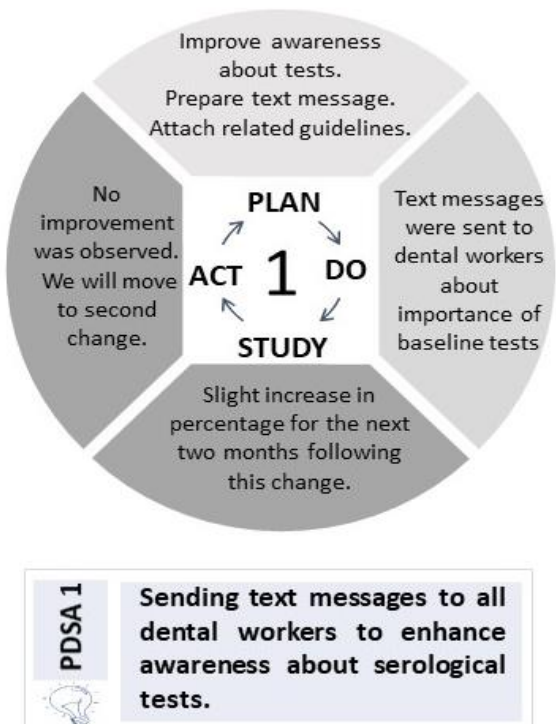
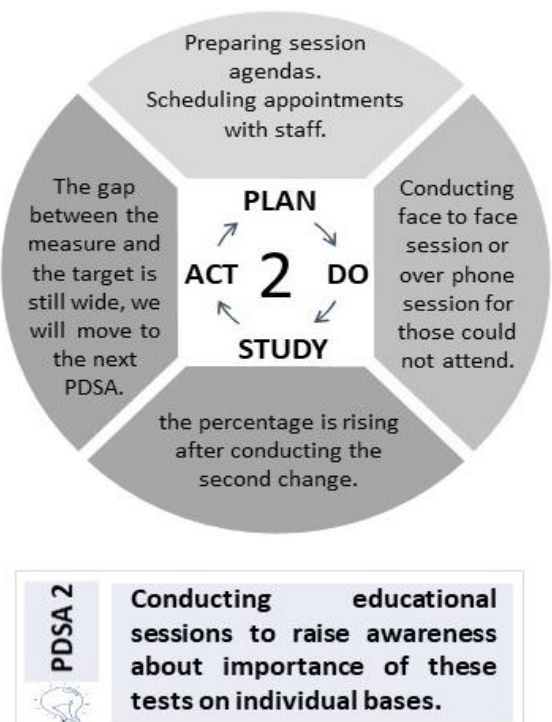

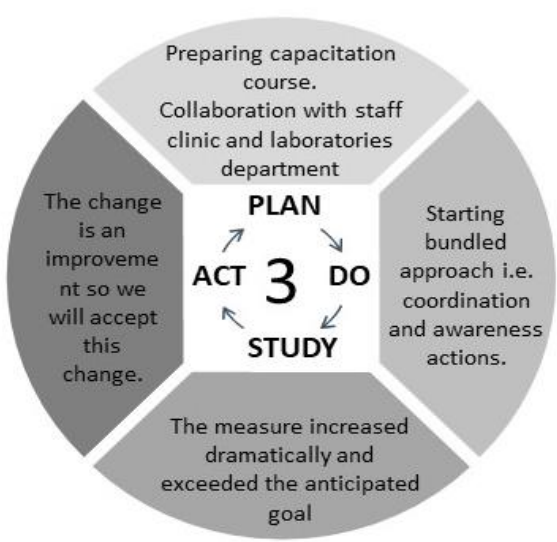

Implementing bundled approach (conducting capacitation courses to enhance awareness and reengineer referral process).

Supplement 1: Depicts the sequential PDSA cycles executed by the team 


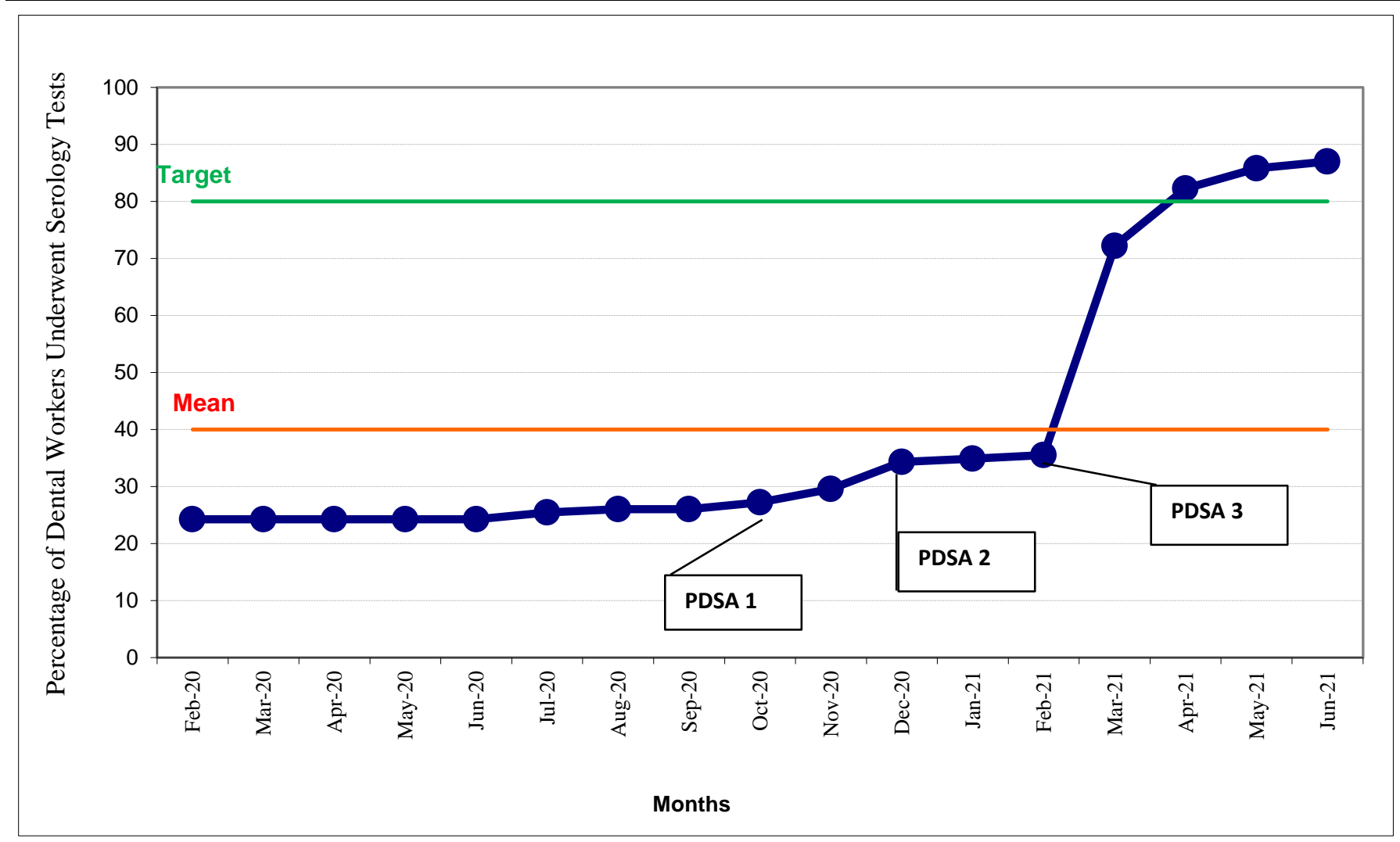

Figure 3: The run chart showing percentage of dental workers underwent serology tests on monthly basis from October 2020 to June 2021.

\section{LESSONS AND LIMITATIONS}

The aim of the current quality improvement project was to increase the percentage of dental workers undergoing serologic tests, which is necessary to maintain laboratory data for dental staff to monitor staff and patient safety. A key lesson learned during the execution was the importance of PDSA cycles, which helped to ensure that at each stage, the intervention was tested before being fully implemented.

Another lesson learned was the gradual progressive nature of building awareness among staff, which also cannot be achieved via one-way messages only, but rather through thorough educational sessions.

Cooperation between multidisciplinary departments, namely occupational health clinic, laboratory, and the dental center on high managerial level, paved the way for the adoption of bundled interventions, which in turn optimized the resultant effect. The high satisfaction level of stakeholders assured the team that this project could be sustained in the future.

Since some changes had a latent effect, the team allowed more time for measurement after testing.

In terms of limitations, although the current work exceeded the target at $87 \%$, we believe that a research gap and significant opportunity for improvement remain. Further projects could raise the measure to higher values, possibly $100 \%$.

Ethical approval: The study was conducted according to the guidelines of the Declaration of Helsinki and approved by Local Ethical Committee.

\section{CONCLUSION}

The project team identified the baseline percentage of dental workers who underwent crucial laboratory investigations, brainstormed the possible causes of the low rate, and developed interventions to address the identified causes. The project has exceeded the targeted value of $80 \%$ (as is evident during the month of June 2021), but the project team acknowledges that continuous work is required to keep the measure above this target. To sustain continued improvement and prevent possible failure, the project team has improved the new re-engineered referral process and mandated educational sessions for all newly hired dental staff. Furthermore, the occupational health clinic will conduct periodic audits to ensure the completeness of laboratory data for each dental worker.

Acknowledgement: The authors acknowledge the staff of the occupational health clinic as well as the laboratory department for their valuable cooperation

Author Contributions: Dr Ahmad contributed in reporting the results and reviewing the manuscript. Dr Layali and Dr Hanady contributed in planning, execution of the project and reviewing the manuscript. Dr Haifa contributed in planning and execution of the project.

Conflict of interest: The author declared no potential conflicts of interest with respect to the research, authorship, and/or publication of this article. This research did not receive and specific grant from funding agencies in the public, commercial, or not-for-profit sectors. 


\section{REFERENCES}

1. Andrew Webb, Simon Finfer, Luciano Gattinoni, Mervyn Singer Oxford Textbook of Critical Care [Internet]. Webb A, Angus D, Finfer S, Gattinoni L, Singer M, editors. Vol. 1. Oxford University Press; 2016. Available from: http://oxfordmedicine.com/view/10.1093/med/9780199600830.001.000 1/med-9780199600830

2. Paiva P, Machado L, Valença A, Moraes R. Uma Proposta de Serious Game para o Ensino de Biossegurança em Odontologia. Pesquisa Brasileira em Odontopediatria e Clínica Integrada. 2013 Jul; 13:135-9.

3. Vargas SC, de Oliveira CF, Renner JDP, Krug SBF, Possuelo L Prevalence of occupational infectious diseases among primary oral health care teams and prevention measures. Revista Brasileira de Medicina do Trabalho. 2020;18(2):149-57.
4. Australian Health Ministers' Advisory Council. Australian Health Ministers' Advisory Council. Australian national guidelines for the management of healthcare workers living with blood borne viruses and Healthcare workers who perform exposure prone procedures at risk of exposures to blood borne viruses [Internet]. 2018 [cited 2021 Oct 23]. Available from: https://www1.health.gov.au/internet/main/publishing.nsf/Content/cdacdna-bloodborne.htm

5. Dental Infection Control Audit. Infection Control Audit Tool [Internet] Riyadh; 2021 [cited 2021 Oct 23]. Available from: https://www.moh.gov.sa/Ministry/MediaCenter/Publications/Document s/MOH-Guidelines-for-re-opening-June-.pdf 